\title{
The distribution of debris flows and debris flow hazards in southeast China
}

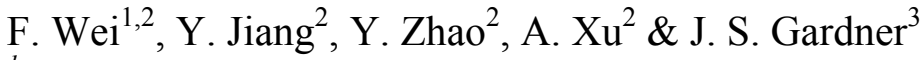 \\ ${ }^{1}$ Key Laboratory of Mountain Hazards and Surface Process, \\ Chinese Academy of Sciences, China \\ ${ }^{2}$ Institute of Mountain Hazards and Environment, \\ Chinese Academy of Sciences, China \\ ${ }^{3}$ Natural Resources Institute, Clayton Riddell Faculty of Environment, \\ Earth and Resources, University of Manitoba, Canada
}

\begin{abstract}
Debris flows commonly occur throughout southern China, posing a hazard to people, property and infrastructure. Although debris flows occur more frequently and with greater magnitude in mountainous southwest China, where they have been studied extensively, their impacts on society are greater in southeast China, where population densities and land use intensities are greater. A number of recent disastrous debris flow events in southeast China have drawn the attention of researchers and the government. Using historical records and field investigations, this paper describes debris flow distribution, casual and contributing factors, hazards and disaster prevention and mitigation measures in southeast China.
\end{abstract}

Keywords: debris flows, distribution, hazard, southeast China.

\section{Introduction}

The west to east topographic profile of China is characterized by three general units and declining elevation. At higher elevation in the west is the QinghaiTibet Plateau, followed by the Yunnan-Guizhou Plateau, Sichuan Basin and Loess Plateau, and finally the lower elevation region of middle and eastern China. Debris flow occurrence is most common in the higher elevation areas of the first two units and the transition zone between them. However, a number of disastrous debris flow events in the third unit, particularly its southeastern part, 
have drawn attention to the debris flow hazard there. Although the distribution density, occurrence probability and scale of debris flow here are less than in southwest China, when they do occur debris flows often result in significant casualties and property loss For example, several debris flows triggered by Typhoon Rananim in the mountainous area in the north of Zhejiang Province on 12 Aug. 2004 produced 42 fatalities and 46.88 million CNY direct economic losses [1]; a debris flow induced by heavy rainfall (208 $\mathrm{mm}$ in 4 hours) in Zhangdun, Jianyang county, Fujian Province on 21 May 1989 caused 47 fatalities, 394 injuries and 46.35 million CNY direct economic loss [2]. As a result of these and other debris flow disasters, more attention is being paid to debris flow hazard research in southeast China. He [3] analyzed the process characteristics, causal mechanisms and principal controlling factors of the main geological disaster sites in Fujian Province, and proposed hazard and disaster mitigation measures ranging from management to technological applications. Wang [4] described the environmental context and current status of geological disasters in Zhejiang Province, and recommended technological and management prevention and mitigation measures. By analyzing flood and torrent hazard conditions and features in Guangdong Province, Lin [5] pointed out problems in the local government's work in organizing flood hazard mitigation and prevention and presented a strategic plan for such work. These researchers analyzed the geological disasters in three provinces of southeast China and offered a framework for hazard and disaster mitigation. However, as yet there is no research or countermeasures intended specifically for debris flow hazard. Using data obtained by field investigation and historical records, this paper examines the distribution of debris flows and describes their characteristics, and discusses countermeasures for debris flow hazard and disaster mitigation in Southeast China.

\section{Characteristics of the study region}

The area under consideration in Southeast China includes three provinces, Zhejiang, Fujian and Guangdong, and is located between $109^{\circ} 27^{\prime} \sim 122^{\circ} 42^{\prime} \mathrm{E}$ and $20^{\circ} 14^{\prime} \sim 30^{\circ} 54^{\prime} \mathrm{N}$ and contains a total area of $429,200 \mathrm{~km}^{2}$ (Fig. 1) .

\subsection{Topography}

The study area lies in coastal area of Southeast China and is part of the third and lowest topographic tier of China (Figure 1). Low-relief hills are widely distributed in the region and plains areas are distributed along the coast. The altitude is less than $500 \mathrm{~m}$ in most of the and the highest elevation is $2,158 \mathrm{~m}$ (Huanggangshan, peak of Wuyi Mountain range) (Figure 2). The low-relief hills taking up more than two thirds of the region consist mainly of the Minzhe hills in Fujian and Zhejiang and the Lingnan hills in the north of Guangdong and the south of Fujian. Influenced by intense crustal movement in the Stage of Yanshan, faults, folds and magmatic intrusions and lava extrusions are common in Minzhe Hills. Topographically, it features small intermountane basins and 


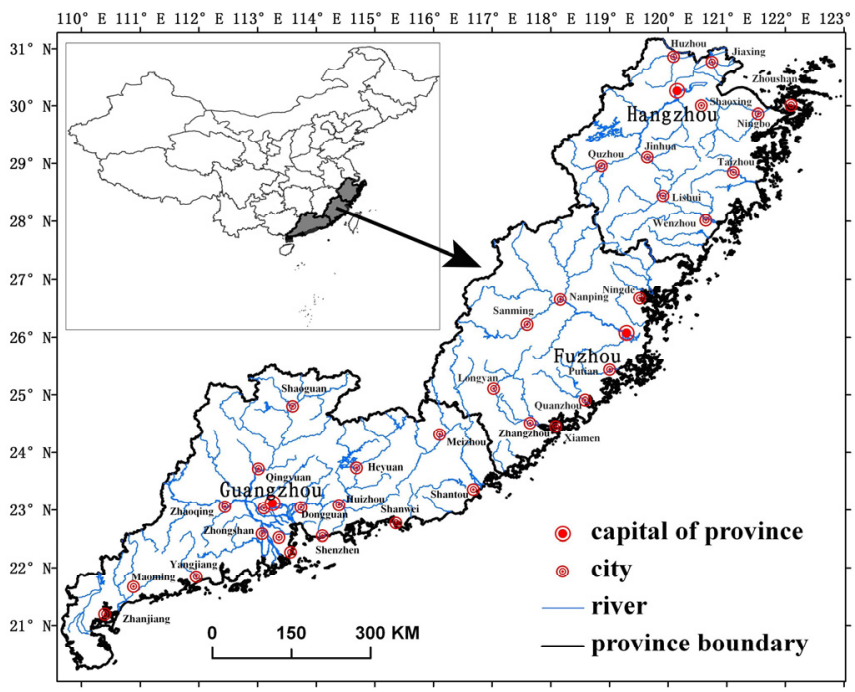

Figure 1: Study region and its position.

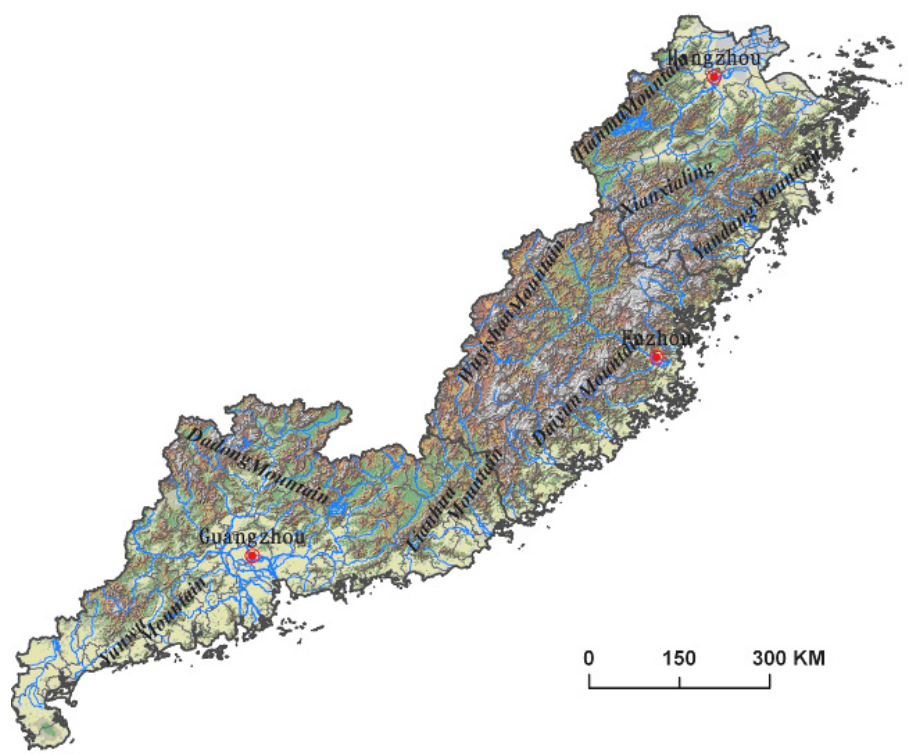

Figure 2: Geomorphologic map of the study region. 
plains lying at the base of the widespread hills. Two ranges paralleling the coast line compose the relief frame of the Minzhe Hills. The westerly range, with average altitude of more than 1,000 m, consists of the Wuyishan Mountains, the Xianxialing Mountains and the Tianmu Mountains. The hills are composed mainly of ancient metamorphic rocks and Paleozoic sedimentary strata. The eastern range, with an average altitude about 800 masl, consists of the Lianhua Mountains, Daiyun Mountains and Yandang Mountains, stretching from southeast to northwest. The mountains are composed mainly of igneous rock and granite. The Lingnan Hills mostly are granite hills with round appearance and strong spherical weathering.

\subsection{Geology}

Tectonic activity has been frequent in the study region as it is located at the intersections of the Pacific Plate, Eurasian Plate and the Philippine Plate. The crustal structure is complex and the topography and geomorphology are strongly influenced by it [6]. The region has experienced several strong tectonic movements. The influence of the Caledon episode is strongest among these movements with the fold mountain paralleling the coast being formed in the Caledonian, with further folding during the Indosinian [7]. Active faults are strongly represented in Fujian and Guangdong. These fault zones generally consist of several faults paralleling the coast in a northeast direction. Some beadshaped basins developed along the edges of these faults (Figure 3) [8].

Massive magmatic intrusion and volcano activity during the Mesozoic produced extensive areas of medium-acidic intrusive rocks and volcanic rocks. Thus, volcanic rocks cover most of Zhejiang and eastern Fujian. Red sandstones

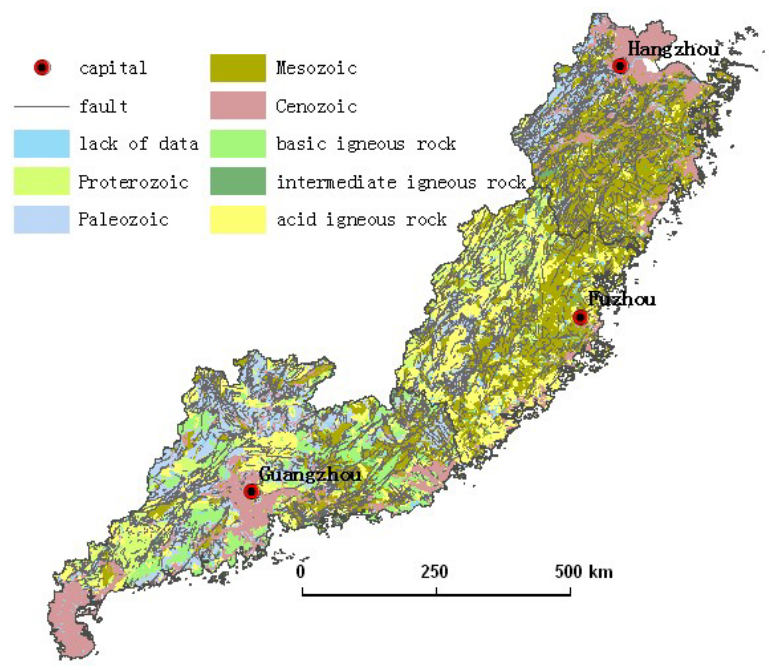

Figure 3: Geological map of the study region. 
and limestones of Cenozoic age are found in intra-montane basins and valleys. The coastal plain and river valleys are covered mainly with Quaternary sediments.

\subsection{Climate}

Southeast China is located in the East Asian monsoon region with a subtropical climate with the exception of southern Guangdong which is characterized by a tropical climate. The average annual temperature decreases from north to south with. Zhejiang in the north has an average annual temperature of $15-18^{\circ} \mathrm{C}$, Fujian in the middle has $20.1^{\circ} \mathrm{C}$ and Guangdong in the south has $19-24^{\circ} \mathrm{C}$. Average annual precipitation is high and increases from north to south and from the coast inland to the mountains. The average annual precipitation at Zhejiang is 980$2000 \mathrm{~mm}$, at Fujian is 1,452 $\mathrm{mm}$ and at Guangdong is 1,300-2,500 mm. The precipitation is distributed unequally during the year with more than $85 \%$ occurring during April to October. Frontal and cyclonic systems generate precipitation with two annual peak periods, one in May and June and the other in August and September. The study region is affected by typhoon very seriously. Most typhoons influencing China land from this region and bring extreme rainfalls, which is the main type of rainfall that induces debris flows.

\section{Debris flow distribution and its principle}

\subsection{Debris flow types}

Debris flows in Southeast China may be divided into two types: slope debris flows and gully or valley debris flows. Much of southeast China is made up of

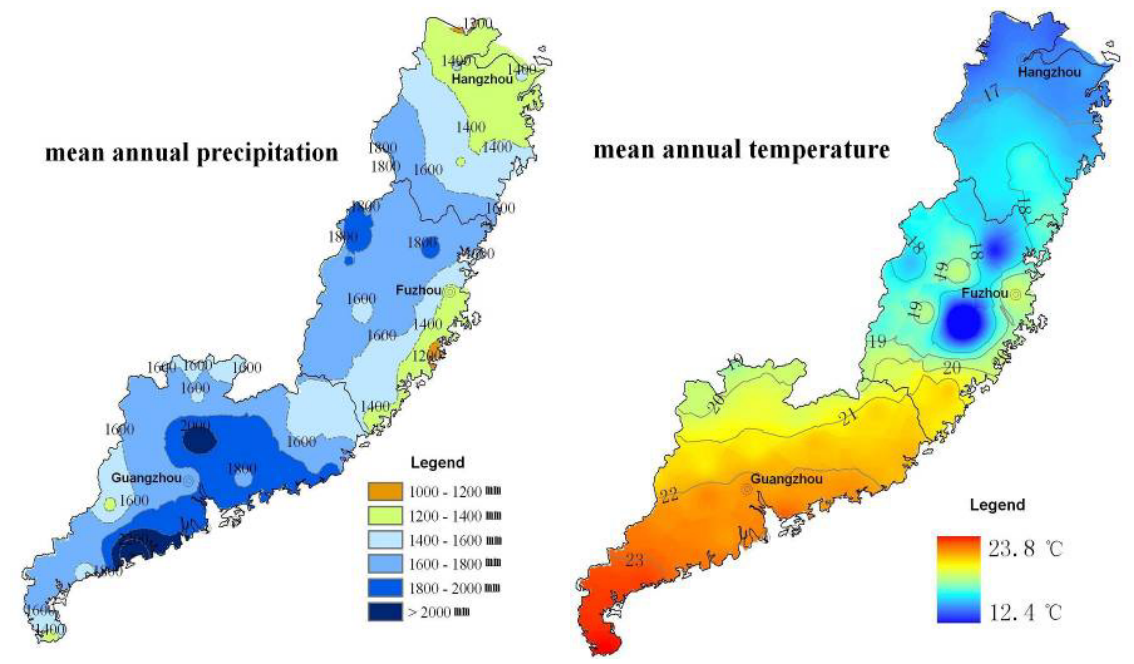

Figure 4: Distribution of mean annual precipitation and temperature. 
low mountains and hills with small altitude difference, making the debris flow tracks relatively short. The main debris flow type is a slope debris flow, meaning that it is initiated and flows on an open slope. Damage done by slope debris flows is usually relatively minor because of the short running distance and low velocity. A second type of debris flow, the gully or valley debris flow originates in a small catchment and follows the path of the main catchment outflow. This type of debris flow has strong damage potential because of long movement distance and high velocity. Although gully or valley debris flows are rare in the study region, most serious debris flow disasters are induced by them. The debris flows discussed in this paper are mainly of the gully or valley type.

The human activities in southeast China are the most intense in China. Wastes produced by road building and mining may accumulate and induce debris flows. For example, the debris flow event of 15 June 2002 in Dalu village, Minqing County of Fujian Province was caused by accumulated waste debris from an expressway construction in the channel of the Dalu valley. This debris flow destroyed a factory built on the fan in the valley and cased more than 10 million $\mathrm{CNY}$ in direct economic loss.

\subsection{Debris flow distribution}

There are 463 known debris flow valleys in Southeast China (Figure 5). 291 debris flow valleys are in Zhejiang Province, distributed in 46 counties; 107 valleys are in Fujian Province, distributed in 38 counties; and 65 valleys are in Guangdong Province, distributed in 24 counties. In Zhejiang Province, debris flows are distributed mainly in the mountains of western and southern Zhejiang,

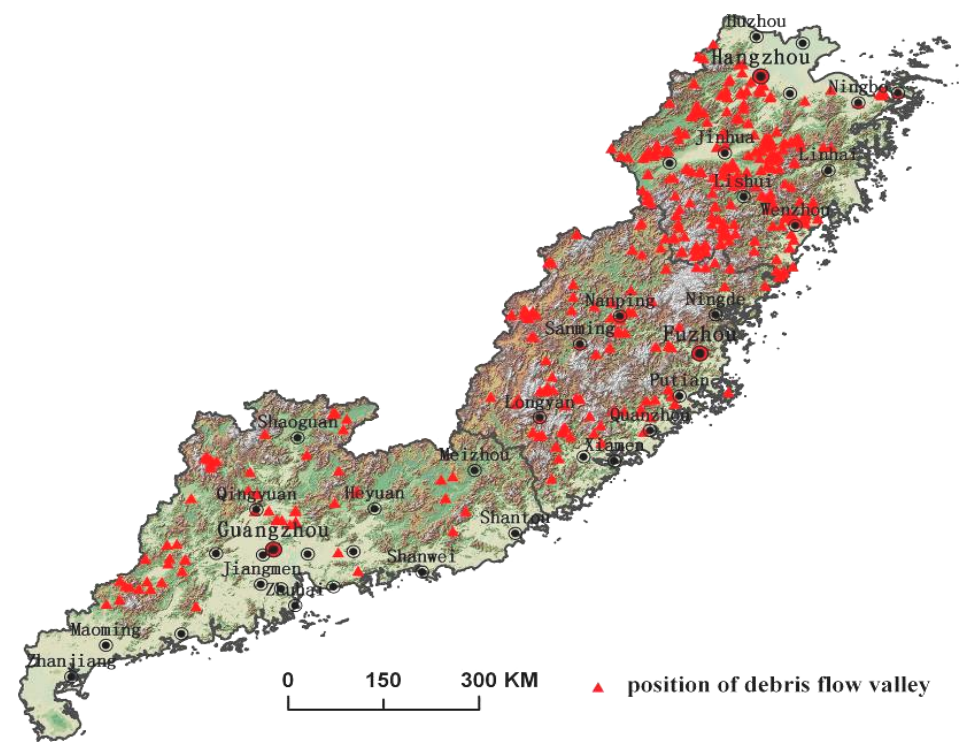

Figure 5: Distribution of known debris flow valleys. 
including Wenzhou, Lishui, Quzhou and Jinhua. In Fujian Province, debris flows are distributed in all mountainous and hilly areas except the coastal area. In Guangdong Province, debris flows are distributed mainly in mountains of northern Guangdong.

In terms of topographic units, Southeast China's debris flows are mainly distributed in the Minzhe Hills and Nanling. In the Minzhe Hills, debris flows are mainly distributed in Yandang-Dalao Mountains, Kuocang-DonggongDaiyun-Bopingling Mountains and Longmen-Xianxia-Wuyi mountains. All of these mountains are oriented parallel to the coast line. In Nanling, debris flows are mainly distributed in Yao Mountains and Jiulian mountains.

\subsubsection{Topographic characteristics}

In order to analyze the debris flow distribution by topography, the study region was divided into grids with the size of $3 \mathrm{~km} \times 3 \mathrm{~km}$. The distribution of known debris flow valleys in the grids with different elevation differences is analyzed and then the probability of debris flow valleys appearing in the grids with different elevation differences is evaluated as in Fig. 6. According to Fig. 6, the probability increases along with a gain in elevation difference. And, the probability increases dramatically after elevation difference reaches $600 \mathrm{~m}$. This result is similar to what has been found in Southwest China but with but some differences. The probability would decrease with gain in when it reaches a specific threshold number in southwest China [9], while it is monotonically increasing in Southeast China cases. This is mainly because Southwest China mostly consists of mid and high mountains with steep slope and large elevation difference, while Southeast China mostly consists of low mountains and hills with small elevation difference.

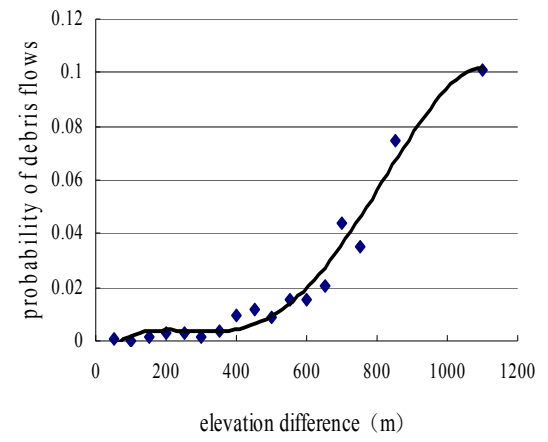

Figure 6: Distribution of debris Figure 7: Distribution of debris flow in topography.

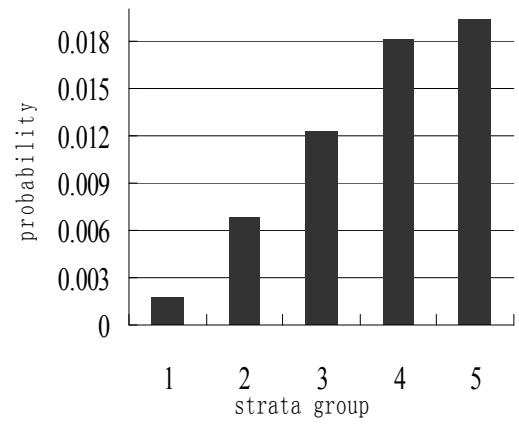

flow by geological strata. 


\subsubsection{Debris flow distribution by geological strata}

In order to analyze debris flow distribution by strata type, the complex strata are classified as five groups (Table 1). This classification is based on the reference 9 and revised according to the research of Zhang et al. [10]. The distribution of known debris flow valleys in five stratum group is analyzed and then the probability of debris flow valleys appearing in each group is evaluated as in Fig. 7. According to Fig. 7, the probability has evident differences in the five groups.

\subsubsection{Debris flow distribution in relation to faults}

In order to analyze debris flow distribution in relation to faults, the fault density in every grid is calculated with GIS tools according to the fault length in each grid and the area of the grid, and then the probability of the known debris flow valleys appearing in the grids with different fault density is evaluated as in Fig. 8. According to Figure 8, the probability of debris flow valleys increases with an increase of fault density.

\subsubsection{Debris flow distribution in time}

Influenced by the monsoon climate, debris flows in Southeast China are mainly distributed in summer (from May to October), and more concentrated during

Table 1: $\quad$ Classification of strata.

\begin{tabular}{|c|c|c|c|}
\hline \multirow{2}{*}{ Category } & \multicolumn{3}{|c|}{ lithology } \\
\hline & Sedimentary rock & Magmatic rock & Metamorphic rock \\
\hline 1 & $\begin{array}{l}\text { Dolomite, charcoal grey } \\
\text { and coarse lamellar } \\
\text { limestone, concreted, } \\
\text { siliceous limestone, } \\
\text { cherty limestone }\end{array}$ & $\begin{array}{c}\text { thick-bedded rhyolite, } \\
\text { thick-bedded andesite, } \\
\text { basalt }\end{array}$ & $\begin{array}{l}\text { Quartz, quartz vein, } \\
\text { diabase, diabase } \\
\text { vein }\end{array}$ \\
\hline 2 & $\begin{array}{l}\text { Quartzy sandstone, } \\
\text { siliceous conglomerate, } \\
\text { bleached limestone, } \\
\text { quartzy siltstone }\end{array}$ & $\begin{array}{l}\text { Fine and medium-grain } \\
\text { granite, diorite, gabbro, } \\
\text { andesite, tuff, rhyolite } \\
\text { porphyry, basic igneous } \\
\text { rock, ultrobasic rock, } \\
\text { alkaline granite, } \\
\text { diabase, porphyrite }\end{array}$ & $\begin{array}{c}\text { Marble, quartz } \\
\text { schist, amphibolite, } \\
\text { serpentine, } \\
\text { metamorphic basalt }\end{array}$ \\
\hline 3 & $\begin{array}{l}\text { Sandstone, marlite, sandy } \\
\text { and siliceous mudstone, } \\
\text { conglomerate }\end{array}$ & $\begin{array}{c}\text { Volcaniclastic rock, } \\
\text { porphyritic coarse- } \\
\text { grained granite, syenite }\end{array}$ & $\begin{array}{c}\text { Schist, slate, } \\
\text { granulite, } \\
\text { metamorphic } \\
\text { liparite, } \\
\text { metasandstone, } \\
\text { gneissose }\end{array}$ \\
\hline 4 & $\begin{array}{l}\text { Shale, siltstone, coal- } \\
\text { bearing strata, semi- } \\
\text { consolidated rock, } \\
\text { unconsolidated sandstone }\end{array}$ & Volcanic debris & Phyllite \\
\hline 5 & $\begin{array}{l}\text { Quaternary loose deposit ( } \\
\text { wash and moraine) }\end{array}$ & $\begin{array}{l}\text { ss, alluvial deposition, di } \\
\text { ild clay, clay, clay sand, }\end{array}$ & $\begin{array}{l}\text { vial deposition, slope } \\
\text { eat, mudstone }\end{array}$ \\
\hline
\end{tabular}




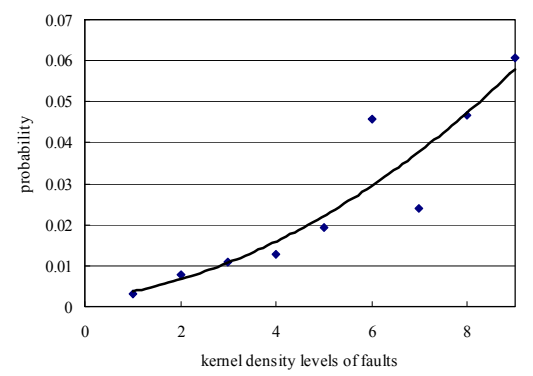

Figure 8: Distribution of debris Figure 9: flow in relation to faults.

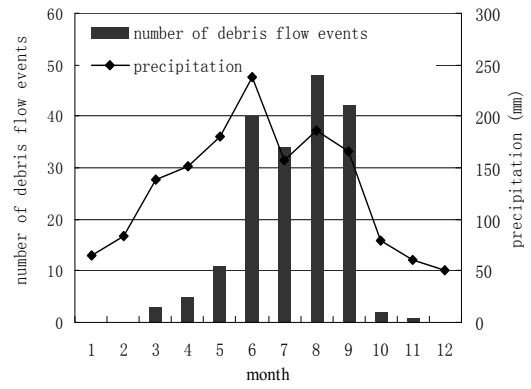

Annual distribution of debris events and precipitation.

June to September. The distribution of debris flow events in the most recent 30 years and average precipitation month by month in southeast China are illustrated in Fig. 9.The distribution of debris flows events in a year takes on a bimodal distribution coinciding with the distribution of precipitation. The first peak appears in June coinciding with the onset of the monsoon, while the other peak in August which is coincident with the typhoon season which often brings very heavy rainfalls.

\section{Countermeasures for debris flow disaster mitigation}

Because of the dense population and highly developed industries and infrastructure in southeast China, debris flow disaster mitigation is very important. According to the characteristics of debris flows noted above, the following countermeasures for debris flow disaster mitigation are proposed.

(1) Identification of debris flow valleys

Debris flow valleys and potential debris flow valleys are often ignored or misjudged in southeast China because debris flow frequency of occurrence is relatively low in most locations, vegetation conditions are good and the traces of past debris flows are not obvious as they are modified by fluvial processes and hidden by vegetation. Almost all of the serious debris flow disasters have occurred in these kinds of valleys. So distinguishing debris flow valleys and potential debris flow valleys is a very important initial countermeasure for debris flow disaster mitigation. The valleys which will be used for buildings and infrastructure must be completely assessed before and construction takes place.

(2) Preventing debris flow disasters by control works

Southeast China has a high population density, and the land resource is very valuable. Though a valley has been identified as a debris flow site, in most instances, the area's land use will not be given up. Thus, debris flow control works seem rather important. Debris flow control works must be constructed in the valleys where debris flows have occurred or have the potential for occurring. 
In addition, the large magnitude of debris flows induced by strong typhoons, as compared with water floods, has to be considered in the design of debris flow control works.

(3) Intercepting floating woods

Because the economy of southeast China is highly urbanized and industrialized, most slopes in the hill and mountain areas have returned to forestland from cropland and the percentage of forest cover is high. As a result, many of the valley debris flows carry large numbers of logs and other vegetative material that adds to the flow magnitude and causes flow blockages at channel constrictions and at bridges and culverts. To prevent this, the logs should be intercepted before they move to control works, bridges and culverts.

(4) Debris flow prediction and warning systems

Most of typhoons approach the study region from the east and southeast and they are observable long before they make landfall, thus making forecasting and warning possible. Typhoons often bring heavy rainfall and trigger hazardous debris flow events. The magnitude of debris flows induced by typhoon rainfall is often very high and the peak discharge is often greater than the design standard of the control works. So debris flow prediction, forecasting and warning are important not only for debris flow valleys without any control works but also for those with control works. Debris flow prediction, forecasting and warning are active measures which may reduce deaths and injuries due to debris flows.

\section{Conclusion}

The number and frequency of debris flows is less in the low relief terrain of southeast China than in high relief southwest China where debris flow have been more commonly studied. However, because of the well-developed economy with its dense population and abundant infrastructure, debris flows pose a more serious risk and often lead to serious disasters in southeast China. Slope debris flows are the most common form in southeast China, but most of the serious disasters are caused by valley debris flows. The rapid development of the region has both exposed more people and property to the hazard and in some cases has contributed to the occurrence of debris flows. Based on the present data, 463 known debris flow valleys are distributed in three provinces of southeast China, but mainly in the Minzhe Hills and the eastern part of the Lingnan Hills, and more occur in Zhejiang and Fujian Provinces than in Guangdong. The debris flow distribution has obvious regularities in topography, stratum, fault and time. The probability of debris flows distribution is advanced with the growths of elevation difference and faults density. The distribution of debris flows events in a year takes on a bimodal distribution coinciding with the prime rain season and the typhoon season. Based on the debris flow characteristics in Southeast China, the best countermeasures for disaster prevention and mitigation are identification of potential debris flow valleys, prevention of debris flows by control works and flow regulation structures, interception of logs and other vegetative material and the use of debris flow prediction and warning systems. 


\section{Acknowledgements}

This research is supported by the Research Fund for Commonweal Trades (Meteorology) (Grant number: GYHY200706037), the Key Project in the National Science \& Technology Pillar Program (Grant number: 2008BAK50B04) and Chinese Academy of Sciences Visiting Professorship for Senior International Scientists (Grant No. : 2009Z2-13).

\section{References}

[1] Yuan, L., Cui, X., Wang, Z., et al. Cause mechanism of Xianrentan debris flow in Yueqing City, Zhejiang Province, Journal of Natural Disasters, 18(2), pp.150-154, 2009.(in Chinese)

[2] Ruan, F., Fang, D., Zhang, Q., et al. Then cause formation and characteristics of the debris flow event on May 21 in Longan, Jianyang. Fujian Soil and Water Conservation, (2), pp.48-52, 1989. (in Chinese)

[3] He, Y. Characteristics and mechanism of major geological hazards in Fujian Province and Protection and controlling method against them. Geology of Fujian, (4), pp.263-271, 1995. (in Chinese)

[4] Wang, J. Current situation of geological disasters and the prevention measures in Zhejiang Province. Journal of Catastrophology, 16(4), pp.6366, 2001. (in Chinese)

[5] Lin, J. How to promote the prevention of mountain torrents disasters in Guangdong Province. Guangdong Water resources and Hydropower, (4), pp.84-85, 2004. (in Chinese)

[6] Zhao, P., Wang, J., Wang, J-A., et al. Characteristics of heat production distribution in SE China. ACTA Petrologica Sinica, 11(3), pp.292-305, 1995.

[7] Ren, J. The Indosinan orogeny and its significance in the tectonic evolution of China. Bulletin of the Chinese Academy of Geological Sciences, (9), pp.31-42, 1984. (in Chinese)

[8] Hu, H., Shen Y. Principal characteristics of vertical crustal deformation in Southeast China. Seismology and Geology, 12(2), pp. 121-130, 1990.

[9] Wei, FQ., Gao, KC., Hu, KH., et al. Relationships between debris flows and earth surface factors in Southwest China. ENVIRONMENTAL GEOLOGY, 55(3), pp.619-627, 2008.

[10] Zhang, J., Wei, FQ., Yu, SJ., et al. Susceptibility analysis of debris flow to rocks based on hydrological characteristics of their weathering products. Chinese Journal of Rock Mechanics and Engineering, 27(11), pp.22272233, 2008. (in Chinese) 